\title{
West African countries plan to strengthen health systems after Ebola
}

\author{
Anne Gulland \\ London \\ The health facilities and infrastructure put in place to help Sierra \\ Leone, Liberia, and Guinea contain the Ebola virus disease \\ epidemic should form the basis of a new health system, the \\ World Health Organization has urged.
}

At a high level meeting on building resilient health systems at WHO's headquarters in Geneva, many delegates said that the equipment and resources provided by non-governmental organisations and donor governments should be used for building health systems after the epidemic.

Marie-Paule Kieny, WHO's assistant director general, told a press conference convened during the meeting that many delegates said it was too early to put a timescale on the proposal, adding, "There need to be transitional plans put in place in order to make sure these assets become a base for future growth in these countries."

She said that building laboratory and surveillance capacity had to go hand in hand with building hospitals and health centres. "One part is seen as building the health system and the other part is seen as security," she said.

"Building resilient health systems will take time and resources and investment and must have a longer term perspective and not just look at short term gains," she added.

Abu Bakarr Fofanah, Sierra Leone's health and sanitation minister, told journalists that health system strengthening was a "process not an event" and that it was impossible to say how long it would take. "In my country we say that when trees fall on top of each other the topmost one must be removed first. That is Ebola-once we get it out of the way we can think about health system strengthening," he said.

Bernice Dahn, chief medical officer of Liberia, told the press conference about the difficulties in providing routine healthcare during the Ebola epidemic. She said that patients were afraid to come to hospital because of fears of contracting the disease and that between February and October this year there were around 6000 deaths from malaria, nearly double the number from Ebola. She said, "In my country $65 \%$ of health facilities are closed because of Ebola ... We could have saved some of these deaths [from malaria] if hospitals were open."
Margaret Chan, WHO's director general, told delegates that the Ebola outbreak had reduced the number of doctors and other healthcare workers in the three most affected countries of Sierra Leone, Liberia, and Guinea. "Prior to the outbreaks, these countries had only one to two doctors to treat a population of nearly 100000 people. That number has been diminished as more than 600 healthcare staff have been infected," she said. Sierra Leone and Liberia have plans in place to increase their numbers of healthcare workers, with the Sierra Leone government planning to waive tuition fees for medical and nursing students.

WHO figures published on 11 December show that there have been 18118 cases of Ebola virus disease in the three most affected countries, including 6533 deaths. Sierra Leone has seen the highest number of cases, at 8014 , followed by Liberia with 7765 and Guinea with 2239.

There has been a spike of cases in Kono, a remote district of eastern Sierra Leone. A rapid response team made up of workers from the health ministry, the US Centers for Disease Control and Prevention, and WHO found 87 bodies piled up at a local hospital. The team responded to a tip off that cases had been unreported.

A WHO statement said that the workers "uncovered a grim scene." It continued, "In 11 days two teams buried 87 bodies, including a nurse, an ambulance driver, and a janitor drafted into removing bodies as they piled up at the only area hospital, ill equipped to deal with the dangerous pathogen. In the five days before the team arrived 25 people died in the hastily cordoned-off section of the main hospital serving as a makeshift Ebola holding centre."

The BMJ has chosen Médecins Sans Frontières as its 2014 Christmas charity. Find out how to donate at http://bit.ly/12pPyH3. Many thanks for your support.

Access all of The BMJs content on the ongoing Ebola outbreak at thebmj.com/ebola.

Cite this as: BMJ 2014;349:97668

๑) BMJ Publishing Group Ltd 2014 